\title{
Analysis of Explanatory and Predictive Architectures and the Relevance in Explaining the Adoption of IT in SMEs
}

\author{
Ojiabo Ukoha \\ University of Maryland, Eastern Shore, \\ Princess Anne, Maryland, USA \\ oukoha@umes.edu
}

\begin{abstract}
Hart O. Awa, Christen A. Nwuche, and Ikechukwu F. Asiegbu University of Port Harcourt, Port Harcourt, Nigeria.
\end{abstract}

sundayeze2001@yahoo.com; [email for Nwuche not available];

ikasie@yahoo.com

\begin{abstract}
This paper critiques the explanatory and predictive architectures of six prominent innovation adoption theories with a view to unraveling their individual capabilities in providing lenses to the understanding of the social and idiosyncratic components of small and medium enterprise (SMEs) in adopting Information Technology (IT). The analysis unravels that the existing theories, not withstanding their strengths, have failed in one way or the other to provide an integrated framework that is comprehensive in explaining and predicting IT adoption behavior by SMEs. However, the paper sought to bridge the gap in knowledge by drawing from the reviewed models, including Social Network Theory (SNT) and Actor-network Theory (ANT), to propose SocioPsycho Networks Complexity Theory (SPNCT). SPNCT integrates social, economic, psychological and other environmental variables of IT decision-making team with a view to providing more comprehensive scholarly lenses for explaining and predicting the idiosyncrasies of each actor. This model is believed to be theoretically sound and practically more realistic.
\end{abstract}

Keywords: SMEs, information technology, innovation, adoption, theory.

\section{Introduction}

Irrespective of size, contemporary firms' survival and growth amidst stiff global competition depends largely on their ability to exploit the ample advantages of Information Technology (IT). Information Technology (IT) has revolutionized and brought exponential changes in every sphere

Material published as part of this publication, either on-line or in print, is copyrighted by the Informing Science Institute. Permission to make digital or paper copy of part or all of these works for personal or classroom use is granted without fee provided that the copies are not made or distributed for profit or commercial advantage AND that copies 1) bear this notice in full and 2) give the full citation on the first page. It is permissible to abstract these works so long as credit is given. To copy in all other cases or to republish or to post on a server or to redistribute to lists requires specific permission and payment of a fee. Contact Publisher@InformingScience.org to request redistribution permission. of life (Mancini, 2009); thus firms must remain strategic and entrepreneurial in their quest to achieve their objectives. The global competitive environment constantly provides business opportunities, and perhaps challenges, that apparently remain unexploited by SMEs (Ramdani, Kawalek, \& Lorenzo, 2009). Information Technology (IT) turns the world flat (Israel, 2007), describes inter- 
actions between technical and social systems (Lee, 2001), and offers a wide range of functions that can be exploited by both large corporations and SMEs. Essentially, firms adopting IT infrastructures have the potential to build enduring customer relationships and achieve competitive advantage. Often, the exploitation of Information Technology (IT) opportunities is hampered or encouraged by some social, organizational, economic factors (Chuang, Nakatani, \& Zhou, 2009; Esteves, 2009; Federici, 2009; Shiau, Hsu, \& Wang, 2009). Small and Medium Enterprises (SMEs) are known to be highly idiosyncratic and complex in their social formation evidenced by their interpersonal relationships with owner families, friends, and other businesses that influence their corporate behaviors (Beckinsale, Levy, \& Powell, 2006; Parker \& Castleman, 2009). These explain why bigger organizations differ significantly from SMEs in their information-seeking practices (Ramdani et al., 2009) and thus research findings on IT adoption in large corporations are yet to find fruitful applications among SMEs (Thong, 1999). This low level IT diffusion among SMEs is worrisome as it affects the development of healthy economies.

Literature provides some specific theoretical frameworks that offer explanatory and predictive insights into IT acceptance in organizations. Most of them concentrate on motivating and/or inhibiting factors affecting IT adoption (e.g.; Brown \& Knewkitipond, 2009; Quaddus \& Hofmeyer, 2007; Roberts \& Toleman, 2007). Perceived benefits, organizational size and readiness, and external pressure (Mehrtens, Cragg, \& Mills, 2001); location, operational supports, cost reduction and social approval (Holsapple \& Sena, 2005; Shiau et al., 2009); and application complexity and the provider perspective (Grandon \& Pearson, 2004) are among the major factors in the IT adoption models. Further, a new micro-organizational research emphasis is on the influence of top management team (TMT) and owner-families on Information Technology (IT) adoption.

Unfortunately, there is no one theory that does complete justice to explaining and predicting the extent of IT adoption by all SMEs. Recognizing that studies on Information Technology (IT) adoption differ in terms of the underlying theories and technologies investigated (Chuang et al., 2009), some of the theories have been improved and even integrated to provide stronger explanatory and predictive values. Perhaps because of researchers' customary inclination to the technology acceptance model (TAM), most existing Information Technology (IT) studies focused primarily upon reviewing literature on technology acceptance instead of providing a comprehensive review on broader issues (Williams, Dwivedi, Lal, \& Schwarz, 2009). Review and meta-analysis of this nature unravels under-explored research issues, selects theories and methods appropriate for investigation (Williams et al., 2009), identifies strengths and weaknesses of pertinent research streams, promote discussion on critical issues and identifies alternative theoretical and methodological perspectives. The suitability of any frameworks is assessed by the extent to which they help in theorizing the Information Technology (IT) artifact.

This paper recognizes the challenges of limited explanatory and predictive powers of each of the IT theories and the idiosyncratic and social contexts of small and medium enterprises (SMEs). Therefore, the paper draws its strengths from critical evaluation of the capability of each theory in explaining and predicting IT adoption behaviors amongst SMEs with a view of proposing an integrated theoretical framework expected (1) to complement existing literature, (2) to guide future researchers, and (3) to further spark off the much glamoured debates and of course richer scholarly development in the field. The paper theoretically assesses the extent of overlaps and usefulness of major IT theories in relations to small and medium enterprises (SMEs) and brings to light contributions that bridge gap in knowledge. 


\section{Technology Acceptance Model (TAM) and Theory of Reasoned Action (TRA)}

The Technology Acceptance Model (Venkatesh \& Davis, 1996) is about the first adoption theory specific to IT. It exerts robust influence on adoption behaviors of SMEs perhaps because ownermanagers are assumed major determinants. TAM provides a basis for unveiling the impacts of external variables on decisions ( $\mathrm{Lu}, \mathrm{Yu}, \mathrm{Liu}, \&$ Yao, 2003). TAM's basic postulates rest on the platform of Theory of Reasoned Action (TRA), which emphasizes that belief systems influence attitude, attitudes in turn shape and lead to intentions, and intentions then generate actions.

According to TAM, perceived usefulness (PU) and perceived ease of use (PEOU) provide the fundamental diagnostic insights into how user attitudes towards intentions to use IT are influenced. Perceived usefulness measures prospective users' subjective probability that using a specific application (e.g., blogs, wikis, or other social software) will increase operational outcomesproductivity, effectiveness and/or profitability (Lu et al., 2003). Technology acceptance model (TAM) posits that perceived ease of use influences perceived usefulness, and that both predict attitudes (Venkatesh \& Davis, 1996) and viral behavior. Perceived usefulness is decomposed into near-term and long-term usefulness (Triandis, 1980). The attainment of perceived near-term usefulness paves way for the actualization of the long-term usefulness. Behavioral intentions are dependent upon perceived near-term usefulness, perceived long-term usefulness, and perceived ease of use. This is buttressed by linking perceived usefulness to motivation theories, where Triandis (1980) extends its domain to Vroom's expectancy theory: the choice of a course of action is driven by its expected consequences. Jiang, Hsu, Klein, and Lin (2000) further expanded PU by developing utilization of the internet technology model to explore user acceptance and proposed that the internet is positively related to the dimensional perceived near-term and perceived longterm usefulness.

Perceived ease of usefulness measures the extent to which a prospective user believes that investments in IT infrastructures attract mental effortlessness (Davis, 1993). Mental effortlessness demanded by IT infrastructures attracts more adoption behavior, and those with perceived complexities and steep learning curve are thought risky to adopt. Perceived ease of usefulness is distinct though it correlates with perceived usefulness. Several studies have been undertaken by scholars to assess perceived usefulness and perceived ease of use trade-off and to determine the impacts of external variables on these two mental determinants but their findings were, however, mixed (Davis, 1993). Nevertheless, empirical findings confirm the positive relationships between ease of use and attitude to use (Moore \& Benbasat, 1991; Venkatesh \& Davis, 1996) and show that perceived ease of use is a proven key determinant of users' intention to accept IT. Clarke's (2000) survey supported this when he ranked PEOU among the five major factors that determine the use of wireless handheld devices in Europe. TAM has received ample empirical validation, application, and replication in terms of its use to explain and predict IT adoption (Venkatesh \& Davis, 1996), however it has been vigorously challenged for falling short of other meaningful variables on user's opinion about specific systems. It overtly neglects the influence of ownerfamilies in IT adoption by SMEs. Therefore, TAM needs to incorporate additional constructs or integrate with other IT acceptance models to make for improved explanatory and predictive utilities (Hu, Chau, Sheng, \& Tam, 1999).

\section{Theory of Planned Behavior (TPB)}

Ajzen's (1991) theory of planned behavior (TPB) seeks to enrich TAM by adding more constructs and placing premiums on specific settings and external variables that influence IT adoption. TPB added subjective norms and perceived behavioral control (such as skills, opportunities, and resources to operate the system) to reflect situations where individuals lack substantial con- 
trol over the intended behavior. Also, TPB assumes that people act in accordance with their behavioral intentions, while intentions, in turn, are shaped by attitudes towards the behavior, subjective norms, and perceived behavioral control. Subjective norm(s) is equivalent to social influences (Taylor \& Todd, 1995); it deals with the extent to which the action is believed by powerful stakeholders as appropriate and the extent of decision-makers' motivation to follow these norms given the environment (Parker \& Castleman, 2009). The perceived behavioral control measures the decision-makers' perception of the feasibility of behavior of interest given some resource constraints such as time, personnel, cash, and consultants (Ajzen, 1991). TPB assumes more expanded in terms of specific information guiding decision but Taylor and Todd (1995) believe that their perceived explanatory and predictive utilities are better enhanced by integrating with TAM in a decomposed form. Riemenschneider, Harrison, and Mykytyn (2003) proposed a series of integrated models using TPB and TAM to investigate Website decision of SMEs and found a smooth fit of the models. Other researchers (Davis, 1993; Venkatesh \& Davis, 2000) sought to validate, modify, extend, and improve TAM under different situations to make for wider applicability in relations to new technologies such as digital interactions.

TPB has its strength in explaining and predicting IT adoption behaviors but, like TAM, it overtly ignores the idiosyncrasies of individual SMEs as well as the complexities of interrelationships between SMEs managers and employees, families, and external parties (e.g.; trading partners, governments, customers, consultants, and competitors). TPB incorporated issues that reflect social norms construct, but studies show that TAM and TPB assume the influence of these external parties on IT adoption to be discrete rather than interrelated. Therefore Parker and Castleman (2009) believe that exploring SMEs' adoption of IT requires more rigorous explanatory theories than just individualistic and parochial theories of TAM and TPB.

\section{Innovation Diffusion Theory (IDT)}

The innovation diffusion Theory (IDT) explains the social and relational processes by which an innovation is communicated to members of a social system via certain channels overtime (Rogers, 1995). This implies that IDT uses four key elements - innovation, communication channel, time, and social system - in explaining and predicting when and how an innovation is adopted or rejected within a social system. The social system includes individuals, informal groups, and organizations with norms expected to influence diffusion behaviors (Parker \& Castleman, 2009). IDT offers a different theoretical framework from those of TRA, TPB, and TAM in explaining and predicting acceptance of IT. TAM, TRA, and TPB often use attitudinal variables to determine behavior. Azjen and Fishbein (1980) assert that most studies that provide explanatory and predictive behavior from attitudinal variables are conducted in the framework of the theory of planned behavior (TPB) and, to a lesser extent, the theory of reasoned action (TRA). IDT recognizes the Bass model (media and word-of-month) (Bass, 1969) as the means through which information about innovation spreads across the social systems. It also identifies five characteristic constructs of an innovation - relative advantage, compatibility, complexity, trialability, and observability - that partially determine adoption behavior. Further, IDT includes innovation decision process, the determinants of rate of adoption, and measure of likelihood of innovation adoption.

It is worthy to note that individual innovation decision process is more applicable to SMEs perhaps because owners are the major determinants of decisions (Butler, Reed, \& Le Grice, 2007; Grandon \& Pearson, 2004). This is a simple process with a high involvement behavior. Unfortunately, a simple approach rarely applies wholly to complex technologies as awareness does not necessarily mean adoption (Simmons, Armstrong, \& Durkin, 2008). Know-how supports adoption behavior for complex innovations (Rogers, 1995) and such knowledge is gained through experiential learning (Attewell, 1992). SMEs' limited resources somehow debar them from such 
behavior (Chuang et al., 2009; Shiau et al., 2009); many fail in their IT adoption because they adopt with partial or without know-how. Attewell (1992) proposed the use of mediating institutions (e.g., application service providers, Internet Service Providers, and Website developers) to reduce the knowledge barriers of potential adopters and increase diffusion because sellers use the experience of previous clients' implementations to build know-how intended to reduce the perceived risk of potential adopters. This is subject to the specialists' knowledge since studies show that they could cause SMEs to develop unfavorable attitude towards IT adoption if they are not proficient enough to handle the rigors involved.

Opinion leadership informally influences opinion follower-ship based on the formers' competence, social accessibility, and norm conformity (Parker \& Castleman, 2009). Diffusion of innovation is effective among homophilous groups (people with overlaps in perspectives) and weak among heterophilous groups (Rogers, 1995). Parker and Castleman (2009) accused Rogers of failing to provide lenses into the multiple social systems of SMEs involving the interplay of families, business networks, local communities, and industries, each with possibly contradicting norms, behavior, and social value systems. Organizational decision process involves a formal structure but SMEs have less formal structures and less rigid decision frameworks and are ideally expected to exploit the opportunities of IT more than large corporations.

Some principal constructs of TAM overlap with those of IDT; both theories show resemblance in their constructs. For instance, the relative advantage and complexity of IDT are synonymous with TAM's PU and PEOU respectively. The other three constructs of IDT - compatibility, trialability, and observability - are often treated as moderating variables that directly exhibit strong interactions with PU and PEOU. This clearly shows that these constructs do not hold equal relevance in predicting user intention to use technology: while PU and PEOU are result-based, the other constructs are experience-based. An integrated and all embracing IT adoption behavior framework from the existing models is imperative. However, empirical inquiries to integrate the theoretical frameworks of technology acceptance model (TAM), theory of planned behavior (TPB), innovation diffusion theory (IDT), and perhaps theory of reasoned action (TRA), and to define relationships among their key constructs in explaining and predicting user acceptance of IT are rarely attempted. Karahanna, Straub, and Chervany (1999) surveyed the pre-and post-adoption beliefs in an attempt to integrate TAM and diffusion theory and concluded that actual users and potential adopters of IT exhibit different attitudinal determinants. For potential adopters, attitude is built by considering a set of richer innovation characteristic constructs; for users, attitude is only based on instrumentality beliefs of the usefulness and perceptions of image enhancements.

\section{Technology-Organization-Environment (TOE) and its Extension}

The Technology Organization Environment framework (Tornatzky \& Fleischer, 1990) assumes a seemingly more generic set of factors that assists to explain and predict the likelihood of IT adoption. Technological context describes the technologies inside and outside the firm; organizational context handles descriptive measures such as firm's size and scope, centralization, formalization, and complexity of managerial structure, the quality of human resource, and the amount of internal slack resources; environmental context measures the influence of industry practice, competition, government and trading partners (Tornatzky \& Fleischer, 1990). The demographic(s) of top management team was subsumed under organizational context. More constructs have continued to be added to TOE framework to enrich its IT adoption explanatory and predictive utilities (Grandon \& Pearson, 2004). A firm's decision on business strategy and business focus, strategic plans, IT adoption, operating weapons, assessment of environment, and approach to strategic issues is shaped by the peculiarity of minds of the decision makers. This belief made Thong (1999) improve upon Technology Organization Environment to Decision Maker Technology Organization 
Environment with the addition of decision makers' characteristics. Analysis of IT adoption behavior seems almost incomplete without such constructs as owners' enthusiasm and growth ambition (Fillis, Johanson, \& Wagner, 2004), top management support and managerial productivity (Grandon \& Pearson, 2004), managers' belief differences (Riemenschneider \& McKinney, 2002), and chief executive officer's knowledge and characteristics (Shiau et al., 2009; Thong, 1999).

The predictive powers of the constructs of decision makers' characteristics have been empirically validated. For instance, age is found to have direct impact on perceived usefulness and complexity and on workers' performance as younger executives appear to be much more associated with corporate growth (Czaja \& Sharit, 1998) or more appealing to fresh and unique ideas (Hambrick \& Mason, 1984). Educational attainment serves as a predictor of a person's value systems and cognitive preferences (Hambrick \& Mason, 1984) and determines consistently the receptivity of an innovation (Becker, 1970); the level of education reflects on personal innovativeness and the propensity to take risk (innovation). Though Chuang, Rutherford, and Lin (2007) believe to the contrary, experience has long been rated a significant predictor of IT adoption in technology acceptance research; favorable experience about a technology in terms of perceived usefulness, perceived ease of use, and other constructs can influence the adoption and use behaviors of a similar one on accounts of stimulus generalization and/or technology cluster.

DTOE framework underscores IDT (Rogers, 1995) in the three groups of adoption predictors leader characteristics, internal characteristics, and external characteristics. IDT, TOE, and DTOE emphasize technological characteristics, which is consistent with TAM's PU and PEOU on potential adopters. Implicit from these is that IT adoption behavior is influenced by technology development, organization's conditions that entails necessary business, and organizational reconfiguration as shaped by industry environment. The integrated TOE and DTOE models with each adoption predictor having different but larger number of constructs than the original, though make for richer theoretical bases, individually and/or collectivity influences adoption drives. Some of the constructs in the adoption predictors are assumed to apply more to large organizations, where clients are sure of continuity and less complaints, than to SMEs, especially in developing and perhaps emerging economies. The limited resources of SMEs make them less strategic; SMEs rarely employ vibrant youth of better academic qualifications who can reposition their corporate missions and ultimately their relationship with trading partners and consumers.

\section{Resources-Based Theory (RBT)}

Resource-based theory believes that for firms to remain significant in their market, they need to position themselves ahead of rivals by embracing IT infrastructures that are strategic in providing customer perceived superior values. Firms develop and exploit assets and competencies needed to build and sustain customer-endorsed and difficult-to-copy distinctiveness (sustainable competitive advantage) borne out of their positioning in its environment (Rivard, Raymond, \& Verreault, 2006), including owner-managers and employee characteristics (Parker \& Castleman, 2009). IT resource adoption is said to occur when an organization acquires and knows how to use them efficiently (Rivard et al., 2006) to reflect on customer service in a manner difficult-to-copy.

Resource-Based Theory (RBT) recognizes the significance of tangible and intangible resources and stipulates the capabilities firms of any sort must acquire to adopt successful IT infrastructures. However, by virtue of utilizing tangible and intangible resources to their fullest potential, RBT places SMEs to a disadvantage position. This is because, though SMEs show flexibility in operations, they suffer limited resource ordeals and owner-family's influence, which sometimes debar them from entrepreneurial and strategic actions needed to exploit full environmental potentials. RBT fails to explain the adoption decision of non-entrepreneurial firms (Parker \& Castleman, 2009), and because external factors most often trigger IT adoption behavior, RBT rarely provides mechanisms for establishing internal IT adoption readiness capabilities, especially for 
SMEs. Thus, RBT does not explain extensively IT adoption process of non-entrepreneurial SMEs.

\section{Michael Porter's Model}

Porter's (1980) generic thrusts (of low-cost leadership, differentiation, and focus), industry forces, and value chain analysis are widely used by firms in attempts to proactively improve their competitive positions. The pervasive and entrepreneurial nature of these models permitted Porter (2001) to propose that their constructs also influence adoption of IT infrastructures by firms of any size. Specifically IT scholars have sought to apply these models to SMEs. Some of the studies investigate how value chain can be used to study SMEs' adoption of Enterprise Resource Planning (Schubert, 2007); Supply Chain Management (Croom, 2005); and Customer Relationship Management ( Buchanan and Gilles, 1990). Others (e.g., Pavic, Koch, Simpson, \& Padmore, 2007) centre on how IT infrastructures under different generic strategies are used by SMEs to proactively gain sustainable competitive advantage.

Undoubtedly, Porter's models explain entrepreneurial and risk-taking situations, where firms proactively seek to maintain and/or enhance their strategic positions. Perhaps they apply more to firms whose commitments to such economic goals is high, risk taking behavior is high, and managerial skills and other major resources needed to recognize opportunities and improve strategic positioning are intact. SMEs fall short of the explanatory values of Porter's models in terms of adopting IT infrastructures. They are known to focus more on the ideals and knowledge of owner-family members (Butler et al., 2007; Galloway \& Mochrie, 2005) and employees' knowledge, power and trust (Al-Qirim, 2005; Beckinsale et al., 2006; Martin, 2005), perhaps irrespective of prevailing environmental realities. These make them less entrepreneurial and less strategic, and to have less resource to proactively manage change to their own advantage.

Porter's externally focused generic strategies integrated with internally focused model of RBT (Ray \& Ray, 2006; Rivard et al., 2006) seems to provide better proactive basis for building SCA for SMEs through adoption of IT. But this integrated model still fails in explaining IT adoption behavior by SMEs because many SMEs show non-entrepreneurial behavior because ownerfamilies, and not environmental realities, significantly determine their strategic positioning in the industry.

\section{Sparking off Modest Scholarly Debates}

SMEs' decision making about adoption of IT infrastructures is highly conceptualized (no two are same) and influenced by array of factors perhaps because of its high involvement trait. Parker and Castleman (2009) assessed theories that explain IT adoption decision by SMEs on account of networks and complex interplay of varying interpersonal relationships and provision of lenses to identify and predict their potential heterogeneity in social context, business, and interpersonal goals. Apparently these theories reviewed are insightful into the social and idiosyncratic nature of SMEs but they are besieged with the ordeals of inadequacy in providing complete or nearcomplete explanatory lenses to IT adoption. TAM narrowed IT adoption influence to only PU and PEOU, and TPB complemented TAM's constructs with perceived behavioral control and subjective norms. Both models, though economic, utilitarian, and attitudinal-based, conspicuously neglected the influences of psychological, social, and interpersonal variables on IT adoption decision. The RBT and Porter's models described IT adoption behaviors only for entrepreneurial and strategic SMEs' handling risk situations, where decisions are proactively made to minimize the surprises of environmental change.

TOE and DTOE models like IDT recognize the interplay of varying complexities of interpersonal relationships with internal and external parties. However, some of their constructs in the adoption 
predictors are assumed to apply more to large firms than to SMEs. IDT has the potential of providing a seemingly more encompassing framework that covers even the IT adoption processes of SMEs, reflecting on SMEs heterogeneity and the adoption decision-making processes. The obvious limitation of IDT is that it ignores psychological drivers and barriers. It is not specific to IT and does not provide lenses into the multiple social systems within which SMEs make decisions. SME's decisions are shaped by owner families, business networks, local communities, and industries each with possible varying norms, behaviors, and value systems. Hence the need for an integrated theoretical base that will explain SME's IT adoption behavior better.

\section{Proposed Model of SPNCT}

This paper proposes Socio-Psycho Networks Complexity Theory (SPNCT) as a complementary and integrated framework (see Figure 1). SPNCT is an extension of TAM2 and a bit broader than Actor-network Theory (ANT) and even Social Network Theory (SNT). TAM2 improves upon TAM1 (Moore \& Benbasat, 1991), ANT uses human and non-human actors such as computer software, standards, and hardware to explain adoption behavior (Balkundi \& Kilduff, 2006; Tatnall \& Burgess, 2002), and SNT uses structures and processes of social system. ANT handles the role of technology in social settings and the processes by which technology influences and is influenced by social elements overtime (Mahring, Holmstrom, Keil, \& Montealegre, 2004). Also, SPNCT integrates RBT and Porter's model; only, unlike RBT and Porter's model, it assumes that in addition to economic goals, actors have non-economic social capitals upon which social network resources rest. SPNCT recognizes every SME as idiosyncratic and social formation and assumes strategic choices are shaped by the interpersonal and cognitive bases of powerful actors, who perhaps exhibit demographic differences. It believes that social network has the capability of assisting SMEs to access, share, and gain external social capitals that assist to build competencies.

Figure 1 shows five interrelated adoption predictors and drivers, each with different sets of constructs. While economic/technical dimension handles more of utilitarian constructs as TAM and TPB, social dimension seeks for interrelationships amongst actors (managers and ownerfamilies). The decision-makers' dimension relates to demographic variables of actors and other stakeholders, and environmental dimension handles descriptive issues of the firm. SPNCT adds psychological and some more environmental drivers to provide richer constructs. Psychological values measure overt and covert behavior of actors which, according to Moore and Benbasat (1991), cover voluntariness and trialability, while environmental variables, in addition to those of Tornatzky and Fleischer (1990), relate to organization mission, facilitating conditions, and owner family influences. The social network requires studying group behavior, whereas the psychological network studies individuals in the group using such theories as psychographics, perception, attitude, and personality. SPNCT demands that the economic goals and of course the IT adoption behavior by SMEs require a careful understanding of the interplay of group relationship, the group ties/cohesiveness, and the individuals that make-up the groups. 


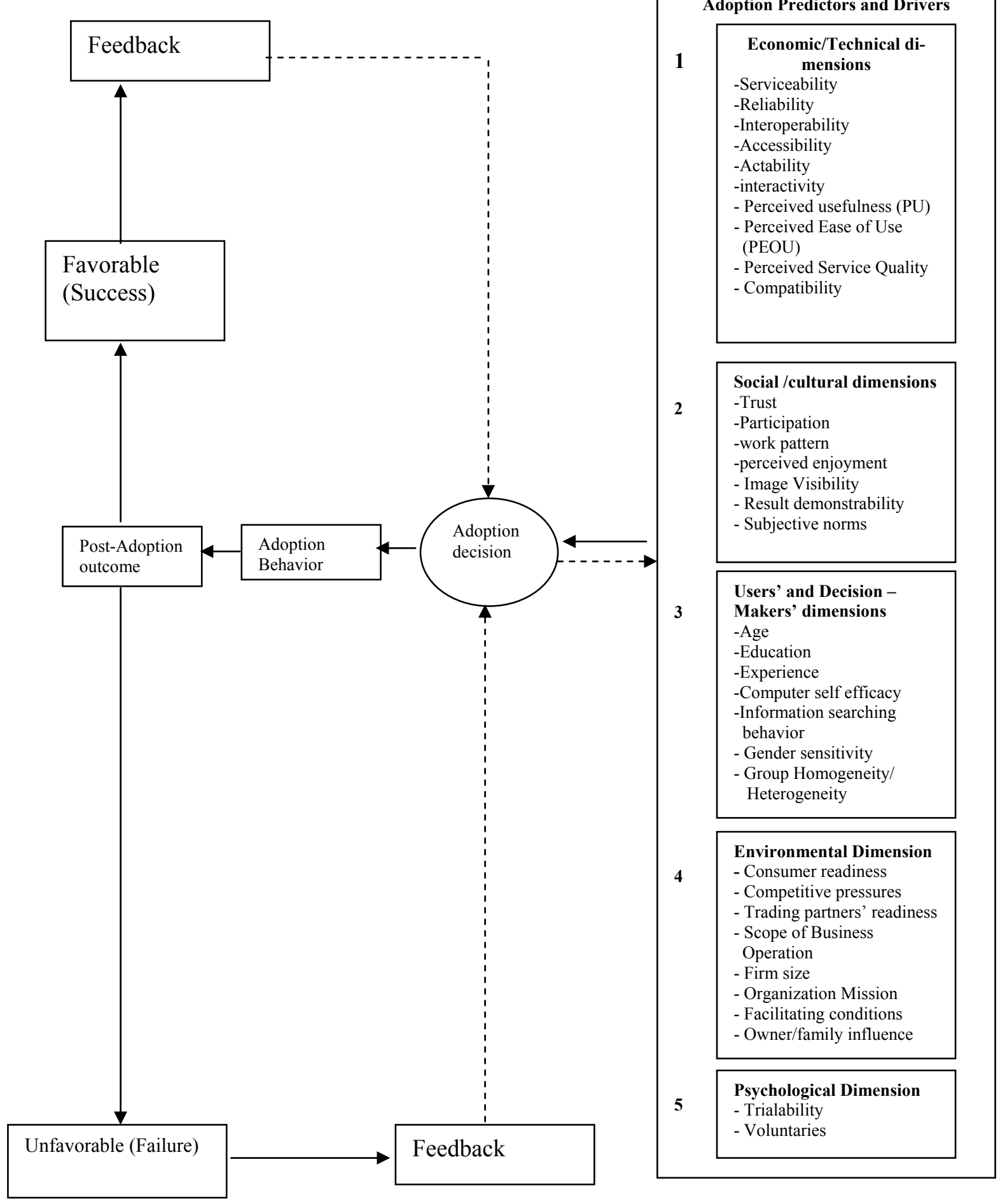

Figure 1: The SPNCT Integrated Model of Innovation Adoption and Use Determinants

However, no mutual exclusiveness exists amongst these adoption predictors; a complete or nearcomplete study of IT adoption amongst SMEs must encapsulate all of them, including their individual constructs. The constructs may not be exhaustive; analysts may keep improving upon them to the advantage of SMEs' flexibility. Since IT adoption is a high involvement decision, the figure shows that the attitude of social actors of SMEs, as inscribed in their choice, is formed based 
on conscious assessment of the perceived predictors and the constructs therein. Actors are brought into social context (Parker \& Castleman, 2009); they form social ties based on their cohesiveness in terms of the perceptual, physiological (Bitner, 1992), psychological, economic, and perhaps political values attached to technology development. Members of such group (e.g., managers and owner-families) interact and share opinions frequently, are in close contact, and are subsets of actors in a network with strong ties (homophilous). Weak ties are also recognized on the strength that some degree of heterophily must exist within the social systems for informed innovation to occur. A careful analysis of this leads to understanding adoption decision and adoption behavior of SMEs. Feedbacks emanates in the form of post-adoption behavior and goes to reflect experience-based judgment and prior knowledge. Such experience reduces the perceived risks of future actions.

\section{Conclusion}

Information Technology revolutionizes the world as everything connects everything else. The adoption of IT by business organizations has been an object of wide scholarship. Scholars and practitioners alike have been inescapably engulfed by the quest for the development of conceptual armory that offers explanatory and predictive utilities to IT adoption behavior of SMEs. Basically, the essence of innovation adoption theories is to acquaint strategists with states of nature and how to convert potential adopters to actual adopters and to turn the latter to product supporters and viral. This paper makes a systematic critique of a few popular IT adoption models as they apply to SMEs and attempts to provide current state of play with a view to developing a more integrated and practically realistic framework that will not only contribute to knowledge but will spark off more scholarly debates.

SMEs are recognized as highly socio-economic and idiosyncratic formations and, thus, need IT adoption theories that inculcate these and their psychological uniqueness relative to large organizations. Like large organizations, SMEs pursue pecuniary and non-pecuniary goals simultaneously but their future positioning is highly shaped by owner-managers' influences and others. The efficacy of IT adoption theories lies on their ability to take into account these multiple goals and complex inter-personal relationships. The analysis in the paper shows that the existing theories, not withstanding their strengths, have failed in one way or another to provide an integrated framework that is comprehensive in explaining and predicting IT adoption behavior by SMEs. While some theories reviewed were better than others, none did complete justice; each conspicuously neglected one or more important constructs. Technology Acceptance Model (TAM) and Theory of Planned Behavior (TPB) are predominantly traditional, utilitarian, and attitudinal based. Resource-Based Theory (RBT) and Porter's Models assume that SMEs exclusively pursue pecuniary ends; and Technology- Organization-Environment (TOE) and DTOE models assume IT adoption behavior as a collection of mediating barriers and drivers. The Innovation Diffusion Theory (IDT) is applauded for recognizing adoption categories reflecting on SMEs' heterogeneity and the adoption decision-making processes bearing in mind the complex interplay of interpersonal relationships.

The socio-psycho networks complexity theory (SPNT) proposed by this paper is a bold step toward bridging the gap. SPNCT is assumed to be more encompassing and more holistic in approaching the integrative complex environmental factors that determine and shape the likelihood of IT adoption by SMEs. In addition to the existing body of knowledge on IT adoption by SMEs, the model captures the psychological angle and beefs up the constructs of the environment as a driver. While this is an honest contribution to IT adoption knowledge armory, it is hoped that it will trigger off further scholarships and provide a more integrative model that encapsulates larger number of key adoption drivers and predictors. 
Ukoha, Awa, Nwuche, \& Asiegbu

\section{References}

Ajzen, I. (1991).The theory of planned behavior. Organizational Behavior and Human Decision Processes, 50(2), 179-211.

Ajzen, I., \& Fishbein, M. (1980). Understanding attitudes and predicting social behavior. Englewood Cliffs, New Jersey: Prentice-Hall.

Attewell, P. (1992). Technology diffusion and organizational learning: The case of business computing. Organization Science, 3(1), 1-19.

Al-Qirim, N. (2005). An empirical investigation of an e-commerce adoption capability model in small businesses in New Zealand. Electronic Markets, 15(4), 418-437.

Balkundi, P. \& Kilduff, M. (2006). The ties that lead: A social network approach to leadership. The Leadership Quarterly, 17(4), 419-439.

Bass, F. (1969). New product growth model for consumer durables. Management Science, 15(January), 215-227.

Becker, H. (1970). Sociometric location and innovativeness: Reformulation and extension of the diffusion model. American Sociological Review, 35, 267-303.

Beckinsale, M., Levy, M., \& Powell, P. (2006). Exploring internet adoption drivers in SMEs. Electronic Markets, 16(4), 361-370.

Bitner, M. (1992). Servicescapes: The impact of physical surroundings on customer and employees. Journal of Marketing, 56, 57-71.

Brown, D., \& Kaewkitipong, L. (2009). Relative size and complexity: E-business use in small and medium sized tourism enterprises in Thailand. Journal of Enterprise Information Management, 22(1/2), 212231.

Buchanan, R., \& Gilles, C. (1990). Value managed relationships: The key to customer retention and profitability. European Journal of Management, 8(4), 205-215.

Butler, A., Reed, M., \& Le Grice, P. (2007). Vocational training: Trust, talk, and knowledge transfer in small businesses. Journal of Small Business and Enterprise Development, 14(2), 280-293.

Chuang, T., Nakatani, K., \& Zhou D. (2009). An exploratory study of the extent of information technology adoption in SMEs: An application of Upper Echelon Theory. Journal of Enterprise Information Management, 22(1/2), 183-196.

Chuang, T., Rutherford, M., \& Lin, B. (2007). Owner/manager characteristics, organizational characteristics and IT adoption in the SMEs. Journal of Management \& Enterprise Development, 4(6), 619-634.

Croom, S. (2005). The impact of e-business on supply chain management: An empirical study of key developments. International Journal of Operations \& Production Management, 25(1), 55-73.

Czaja, S., \& Sharit, J. (1998). Age difference in attitudes towards computer. Journal of Gerontology Series B: Psychological Sciences, 53(5), 329-341.

Clarke, C. (2000). Coming attraction. Wireless Review, 17(12), 12-16.

Davis, F. (1993) User acceptance of information technology: System characteristics, user perceptions and behavior impacts. International Journal of Man-Machine Studies, 38, 475-487.

Esteves, J. (2009). A benefits realization road-map framework for ERP usage in small and medium-sized enterprises. Journal of Enterprise Information Management, 22(1/2), 25-35.

Federici, T. (2009). Factors influencing ERP outcomes in SMEs: A post-introduction assessment. Journal of Enterprise Information Management, 22(1/2), 81-98.

Fillis, I., Johanson, U., \& Wagner, B. (2004). A conceptualization of the opportunities and barriers to ebusiness development in the small firms. Journal of Small Business and Enterprise Development, 10(1), 336-344. 
Hambrick, D., \& Mason, P. (1984). Upper echelons: The organization as a reflection of its top managers. Academy of Management Review, 9(2), 193-205.

Holsapple, C., \& Sena, M. (2005). ERP plans and decision-support benefits. Decision Support Systems, $38(4), 575-590$.

Hu, P., Chau, P., Sheng, O., \& Tam, K. (1999). Examining the Technology Acceptance Model using physician acceptance of telemedicine. Journal of Management Information Systems, 16(2), 91-112.

Galloway, L., \& Mochrie, R. (2005). The use ICT in rural firms: A policy-oriented literature review. Info, $7(3), 33-46$.

Grandon, E., \& Pearson, J. (2004). Electronic commerce adoption: An empirical study of small and medium US business. Information and Management, 42(1), 43-52.

Israel, S. (2007, July 5). SAP global survey: Doc Searls' global neighbourhoods [Web log post]. Retrieved from http://redcouch.typepad.com/weblog/2007/07sap-global-su-1.htm1

Jiang, J., Hsu, M., Klein, G., \& Lin, B. (2000). E-commerce user behaviour model: An empirical study. Human Systems Management, 19(4), 265-276.

Karahanna, E., Straub, D., \& Chervany, N. (1999). Information technology adoption across time: A crosssectional comparison of pre-adoption and post-adoption beliefs. MIS Quarterly, 23(2), 183-213.

Lee, A. (2001). Editorial. MIS Quarterly, 25(1), iii-vii.

Lu, J., Yu, C., Liu, C., \& Yao, J. (2003). Technology Acceptance Model for wireless internet. Internet Research: Electronic Networking Applications and Policy, 13(3), 206-222.

Mahring, M., Holmstrom, J., Keil, M. \& Montealegre, R. (2004). Trojan actor-networks and swift transaction: Bringing actor-network theory to IT project escalation studies. Information Technology and People, 17(2), 210-238.

Mancini, J. (2009). The evolution of Web 2.0. Infonomics, March-April, 8.

Martin, L. (2005). Internet adoption and use in small firms: Internal processes, organizational culture and the roles of the owner-manager and key staff. New Technology, Work, and Employment, 13(2), 147 159.

Mehrtens, J., Cragg, P., \& Mills, A. (2001). A model of internet adoption by SMEs. Information \& Management, 39(3), 165-176.

Moore, G., \& Benbasat, I. (1991). Development of an instrument to measure the perceptions of adoption in information technology innovation. Information Systems Research, 2(3), 192-222.

Parker, C., \& Castleman, T. (2009). Small firm e-business adoption: A critical analysis of theory. Journal of Enterprise Information Management, 22(1/2), 167-182.

Pavic, S., Koch, S., Simpson, M., \& Padmore, J. (2007). Could e-business create a competitive advantage in UK SMEs? Benchmarking: An International Journal, 14(3), 320-351.

Porter, M. (1980) Competitive strategy: Techniques for analyzing industries and competitors. New York: Free Press.

Porter, M. (2001). Strategy and the Internet. Harvard Business Review, 79(2), 63-78.

Quaddus, M., \& Hofmeyer, G. (2007). An investigation into the factors influencing the adoption B2B trading exchanges in small businesses. European Journal of Information Systems, 16(3), 202-215.

Ramdani, B., Kawalek, P., \& Lorenzo, O. (2009). Knowledge management and enterprise systems adoption by SMEs: Predicting SMEs' adoption of enterprise systems. Journal of Enterprise Information Management, 22(1/2), 10-24.

Ray, A., \& Ray, J. (2006). Strategic benefits to SMEs from third party web services: An action research analysis. Journal of Strategic Information Systems, 15(4), 273-291. 
Riemenschneider, C., Harrison, D., \& Mykytyn, P. (2003). Understanding IT adoption decisions in small business integrating current theories. Information \& Management, 40(4), 269-285.

Riemenschneider, C., \& McKinney, V. (2002). Assessing belief differences in small business adopters and non-adopters of web-based e-commerce. Journal of Computer Information Systems, 42(2), 101-107.

Rivard, S., Raymond, L., \& Verreault, D. (2006). Resource-based view and competitive strategy: An integrated model of the contribution of information technology to firm performance. Journal of Strategic Information Systems, 15(1), 29-50.

Roberts, B. \& Toleman, M. (2007). One-size e-business adoption model does not fit all. Journal of Theoretical and Applied Electronic Commerce Research, 2(3), 49-61.

Rogers, E. (1995). Diffusion of innovations (3rd ed.). New York: Free Press.

Schubert, P. (2007). Business software as a facilitator for business process excellence: Experiences from case studies. Electronic Markets, 17(3), 187-198.

Shiau, W., Hsu P., \& Wang, J (2009). Development of measures to assess the ERP adoption of small and medium enterprises. Journal of Enterprise Information Management, 22(1/2), 99-118.

Simmons, G., Armstrong, G., \& Durkin, M. (2008). A conceptualization of the determinants of small business website adoption: Setting the research agenda. International Small Business Journal, 26(3), 351389.

Tatnall, A., \& Burgess, S. (2002). Using Actor-Network Theory to research the implementation of a B-B portal for regional SMEs in Melbourne, Australia. $15^{\text {th }}$ International Bled eCommerce Conference, 1719 June, Bled, Slovenia.

Taylor, S., \& Todd, P. (1995). Understanding information technology usage: A test of competing models. Information Systems Research, 6(2), 144-174.

Thong, J. (1999). An integrated model of information systems adoption in small businesses. Journal of Management Information Systems, 15(4), 27-31.

Tornatzky, L., \& Fleischer, M. (1990). The process of technology innovation. Lexington, M.A: Lexington Books.

Triandis, H. (1980). Values, attitudes, and interpersonal behavior. Nebraska Symposium on Motivation, 1979: Beliefs, Attitudes, and Values. Lincoln: University of Nebraska Press.

Venkatesh, V., \& Davis, F. (1996). A model of the antecedents of perceived ease of use: Development and test. Decision Science, 27(3), 451-481.

Venkatesh, V., \& Davis, F. (2000). A theoretical extension of the Technology Acceptance Model: Four longitudinal field studies. Management Sciences, 46(2), 186-204.

Williams, M., Dwivedi, Y., Lal, B., \& Schwarz, A. (2009). Contemporary trends and issues in IT adoption and diffusion research. Journal of Information Technology, 24, 1-10. 


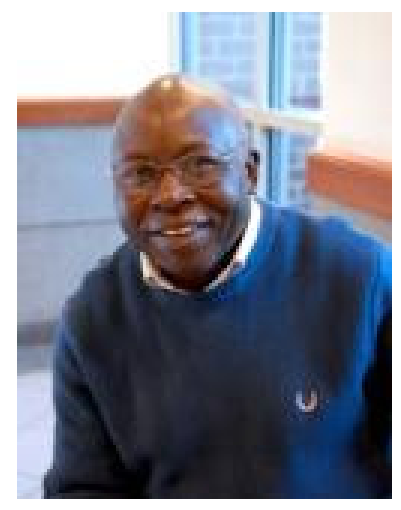

\section{Biographies}

Dr. Ojiabo Ukoha is a Lecturer in the Department of Mathematics and Computer Science at the University of Maryland Eastern Shore. He received his doctorate from the UMES in Organizational Leadership concentration in quantitative modeling and holds an M.B.A. from Kennesaw State University and an M.S. in pure Mathematics from Clark Atlanta University. His research interests include the infusion of technology into mathematics instruction, application of confirmatory and exploratory factor analysis for applied research, and recruiting and retaining low-income students in computer science and other STEM disciplines. His first book titled "Confirmatory Factor Analysis, Basics, Concepts, and Measuring" was published in 2010 by Lambert Academic Publishing Saarbucken Germany, ISBN: 978-3-8383-3170-6.

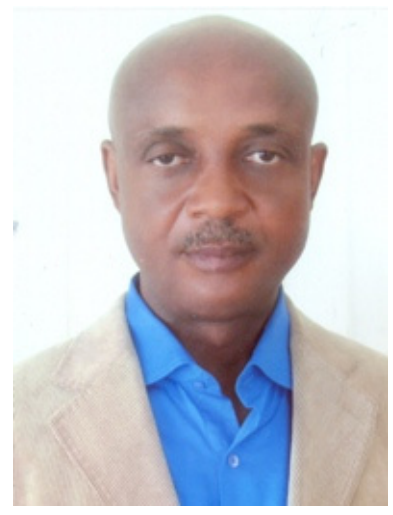

Hart O. Awa, M.Sc; MBA is a business consultant, a lecturer grade 1 and a Ph.D candidate of the Department of Marketing, Faculty of Management Sciences, University of Port Harcourt, Nigeria. He has demonstrated his academic prowess by authoring and co-authoring books and scholarly articles and delivering position papers in local and international conferences. Some of his articles appeared in reputable journals of the United States, United Kingdom, Canada, and Asia. Hart's research interest spans user collaboration and value creation, consumer psychology, application of IT to businesses, Relationship Marketing Orientation (RMO) and Customer Relationship Management (CRM), Public Sector and not-for-profit Marketing, Health-care Marketing, Strategic Market Planning, and Promotion Management.

[Biographies for Christen A. Nwuche and Ikechukwu F. Asiegbu not available.] 